\title{
Mass Transfer, Fluid Flow and Membrane Properties in Flat and Corrugated Plate Hyperfiltration Modules
}

\author{
I.G. RÅCZ, J. GROO'T WASSINK and R. KLAASSEN
}

Department of Chemical Engineering, Twente University of Technology, P.O. Box 217, 7500 AE Enschede (The Netherlands) Tel. (53) 893019; telex 44200

(Received June 16, 1986)

\section{SUMMARY}

Concentration polarisation, decreasing the efficiency in membrane separation processes, can be reduced by increasing mass transfer between membrane surface and bulk of the feed stream. Analogous to techniques used in plate heat exchangers efforts have been made to enhance mass transfer in a plate hyperfiltration module by using a corrugated membrane in stead of a flat one. The corrugations are pressed into an originally flat membrane. These corrugations do not only have an influence on the mass transfer, but also on such membrane properties as salt and water permeability. Corrugations enhance mass transfer in a more effective way than increase of flow rate does.

The effect of the corrugations on membrane properties shows a large spread. For corrugated membranes prepared by our group, flux increases of $100 \%$ at almost the same or even slightly higher retentions have been obtained.

Keywords: membrane filtration, concentration polarization, corrugated membrane, mass transfer enhancement.

\section{INTRODUCTION}

Membrane filtration is a process of continuously increasing interest. Among the different membrane filtration processes hyperfiltration is used rather frequently in commercial installations, for example the desalination of sea or brackish water.

One of the main problems occurring in hyperfiltration installations is the accumulation of salt at the membrane-saltwater interface, also called concentration polarisation. Concentration polarisation can be reduced by enhancement of the mass transfer between membrane-saltwater interface and bulk of the feed stream.

In our preliminary experiments we have tried to increase the mass transfer in a plate hyperfiltration module by using a corrugated membrane in stead of 
a flat one. This technique is analogous to techniques used in plate heat exchangers. We assumed that the corrugations would promote turbulence preferentially near the wall region, causing less pressure drop in the channel along the membrane than other techniques which promote turbulence in the entire feed stream, for example higher flow rates along the membrane or the application of static mixers in the main stream $[1,2]$.

The influence of corrugations on mass transfer, pressure drop and membrane properties has been investigated in our experiments. An influence on structure and properties of the membrane was expected because the corrugations are pressed into an originally flat surface membrane: thereby introducing stresses and strains in the membrane.

\section{TURBULENCE PROMOTERS}

Certain types of corrugated or furrowed membranes are used in membrane oxygenators $[3,4]$. In such a haemodialyser, using pulsating blood and dialysate flow through furrowed channels, high mass transfer rates have been achieved by the mechanism of vortex mixing. Because of the low flow rates and the pulsating flow this mechanism is not directly applicable to hyperfiltration.

Another field of interest, with respect to the turbulence-promoting profiles used, is that of plate heat exchangers. The main goal of the research done in this field concentrates on determination of a suitable profile of the plate in order to reach maximum heat transfer at a low pressure drop. There are many articles published on this subject $[5,6]$ in which a large number of profiles has been investigated. The constraint in using profiles from plate heat exchangers in a hyperfiltration module is that it should not damage the membrane. This may happen if the profile is pressed into an originally flat membrane. Tearing of the membrane occurs especially when the profile has elements with sharp angles or edges. We therefore have chosen half cylinders as turbulence promoters on the membrane surface.

The mechanism of the half cylinders as turbulence promoters on the membrane can be explained as follows: fluid eddies caused by the cylinders follow each other quickly, leaving insufficient length of channel through which the fluid can flow undisturbed, thus reducing build-up of a boundary layer at the membrane-salt solution interface.

\section{HYPERFILTRATION MODEL}

To determine the membrane properties and the mass transfer coefficient the solubility-diffusion model for the membrane and the film model for mass transfer have been used. The equations describing the model are:

$J=A \cdot(\Delta P-\Delta \pi)$ 
$\Delta \pi=R \cdot T \cdot i\left(C_{w}-C_{p}\right)$

$J_{s}=B \cdot\left(C_{w}-C_{p}\right)$

$\theta=\mathrm{e}^{J / k}$

$\theta=\left(C_{w}-C_{p}\right) /\left(C_{f}-C_{p}\right)$

$J_{s}=J \cdot C_{p}$

where

$J \quad-$ volumetric flux of water (solvent) through the membrane $\left(\mathrm{m}^{3} \mathrm{~m}^{-2}\right.$ $\left.\mathrm{s}^{-1}\right)$

$A \quad$-water permeability constant $\left(\mathrm{m}^{3} \mathrm{~N}^{-1} \mathrm{~s}^{-1}\right)$

$\Delta P \quad$-hydraulic pressure drop across the membrane $\left(\mathrm{N} \mathrm{m}^{-2}\right)$

$\Delta \pi \quad$-osmotic pressure drop across the membrane $\left(\mathrm{N} \mathrm{m}^{-2}\right)$

$R \quad$-gas constant $\left(\mathrm{J} \mathrm{mol}^{-1} \mathrm{~K}^{-1}\right)$

$T$-temperature (K)

$i$-number of independent particles per dissolved mole of salt ( - )

$C_{\mathrm{w}}$-concentration of salt at the membrane--saltwater interface $\left(\mathrm{mol} \mathrm{m}^{-3}\right)$

$C_{\mathrm{p}} \quad$-permeate concentration of salt $\left(\mathrm{mol} \mathrm{m}^{-3}\right)$

$J_{\mathrm{s}} \quad$-salt flux through the membrane $\left(\mathrm{mol} \mathrm{m}^{-2} \mathrm{~s}^{-1}\right)$

$B$-salt permeability constant $\left(\mathrm{m} \mathrm{s}^{-1}\right)$

$k \quad$-mass transfer coefficient $\left(\mathrm{m} \mathrm{s}^{-1}\right)$

$\theta \quad$ concentration polarisation modulus $(-)$

$C_{\mathrm{f}}-$ concentration of salt in the feed $\left(\mathrm{mol} \mathrm{m}^{-3}\right)$

Assumptions in this model are:

- only one salt is present as a solute,

- the salt diffusion coefficient is independent of the concentration,

- the fluid is incompressible,

- there is no radial concentration gradient in the bulk of the feed stream,

- the permeation coefficients of salt and water are independent of concentration.

Using this model the membrane properties can be characterised by the water and salt permeabilities $A$ and $B$. The mass transfer is represented by the mass transfer coefficient $k$.

EXPERIMENTAL SET UP

\section{Apparatus}

The apparatus used is shown in Fig. 1. A high-pressure loop with membrane module, circulation pump and some measuring and control instruments are 


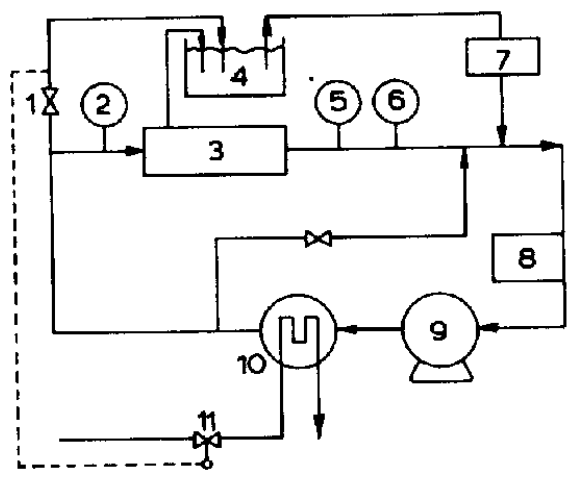

1 pressure control
2 pressure indicator
3 membrane module
4 storage vessel
5 flow indicator
6 pressure control
7 injection purp
8 filter
9 circulation pump
10 heat exchanger
11 temperature control valve

Fig. 1. Hyperfiltration apparatus.

represented. The injection pump provides for the pressure in the system. The membrane module is of a plate type which contains a membrane with a length of $60 \mathrm{~cm}$ and a width of $6 \mathrm{~cm}$. The channel for the feed along the membrane has a width of $6 \mathrm{~cm}$ and a height of $0.6 \mathrm{~cm}$. All equipment is made of stainless steel and is designed to work at pressures up to 60 bar.

\section{Membranes}

The membranes used in the experiments were self-made: they were cast on a polyester nonwoven support. The polymer solution used had the following composition: $25 \% \mathrm{w} / \mathrm{w}$ cellulose acetate, $45 \% \mathrm{w} / \mathrm{w}$ acetone and $30 \% \mathrm{w} / \mathrm{w}$ formamide. Coagulation of the membrane took place in a water bath, at a temperature of $0-1^{\circ} \mathrm{C}$. The membranes were cured for $5 \mathrm{~min}$ in a water bath at $70^{\circ} \mathrm{C}$. This procedure resulted in membranes having a flux of about $30 \mathrm{~lm}^{-2} \mathrm{~h}^{-1}$ and a retention of about $75 \%$, using feed containing $5 \mathrm{~g} \mathrm{l}^{-1} \mathrm{Na}_{2} \mathrm{SO}_{4}$, at 40 bar pressure drop across the membrane. This procedure of preparation was not very reproducible, resulting in a rather large spread in membrane properties.

\section{Support plates}

Corrugated membranes were prepared as follows: the flat support plate in the module is replaced by a support plate with corrugations. Then, a flat membrane is placed on the corrugated plate. By applying pressure the corrugations are pressed into the membrane.

The corrugated support plates have been made by casting a cold-curing resin on a methyl methacrylate basis (Technovit 3040). To drain the permeate, holes of $1 \mathrm{~mm}$ diameter have been drilled into the casted Technovit plate, $1 \mathrm{~cm}$ apart. In our preliminary experiments we have used corrugations of half cylinder shape; the dimensions are shown in Table I. 


\section{TABLE I}

CORRUGATED SUPPORT PLATES

$h=$ height, $l=$ length and $d=$ distance between the corrugations.

\begin{tabular}{lllll}
\hline Plate Nr. & $h(\mathrm{~mm})$ & $l(\mathrm{~mm})$ & $d(\mathrm{~mm})$ & Number of rows \\
\hline 1 & 1.5 & 15 & $4 h$ & 3 \\
2 & 1.5 & 15 & $10 h$ & 3 \\
3 & 1.5 & 15 & $20 h$ & 3 \\
4 & 1.0 & 15 & $10 h$ & 3 \\
5 & 2.0 & 15 & $10 h$ & 3 \\
6 & 1.5 & 5 & $10 h$ & 6 \\
7 & 1.5 & 10 & $10 h$ & 4 \\
8 & 1.5 & 20 & $10 h$ & 2 \\
9 & 1.5 & 10 & $10 h$ & $3 / 4$ \\
\hline
\end{tabular}

The corrugations on plates 1-8 are in line (Fig. 2), on plate 9 they have a staggered configuration (Fig. 3 ).

\section{MEASUREMENTS}

At first, measurements were carried out using a flat membrane and a flat support plate. Then, the support plate was replaced by the corrugated support

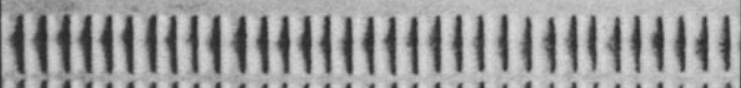

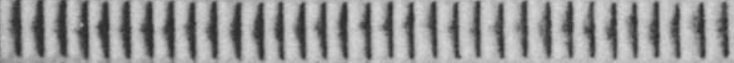

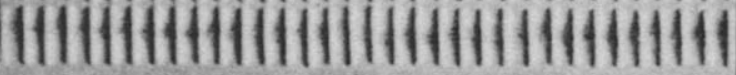

Fig. 2. In-line configuration.

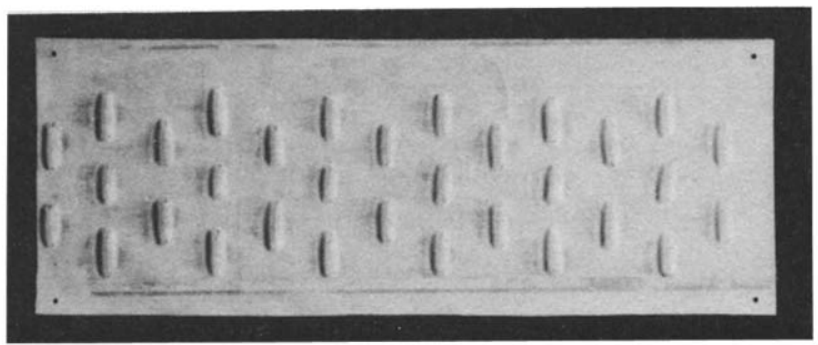

Fig. 3. Staggered configuration. 
plate and the experiment was repeated, using the same membrane. In this way, the influence of the corrugations on the membrane can be observed directly. If different membranes would have been used in the comparative experiments, a large number of membranes would have to be tested in order to obtain reliable average values of the membrane properties.

Before carrying out a measurement, the membranes were compressed for 15 $\mathrm{h}$ at 40 bar pressure. The first measurement is performed with pure water, because in this case osmotic pressure can be neglected and a special form of Eq. (1) can be used:

$J_{p}=A \cdot \Delta P$

The pure water flux, $J_{\mathrm{p}}$, and the pressure drop across the membrane, $\Delta P$, are measured. By means of Eq. (7) the water permeability constant $A$ can be derived.

The next step is to add about $5 \mathrm{~g} \mathrm{l}^{-1} \mathrm{Na}_{2} \mathrm{SO}_{4}$ to the feed water. When the salt concentration in the feed stream is stationary, salt water flux $J$, feed and permeate concentration $C_{\mathrm{f}}$ and $C_{\mathrm{p}}$, temperature $T$ and pressure difference across the membrane $\Delta P$, are measured. Knowing the value of $A$ and using the Eqs. (1-6), $\Delta \pi, C_{\mathrm{w}}, \theta, k, J_{\mathrm{s}}$ and $B$ can be calculated.

RESULTS

\section{Membrane properties}

Pressing corrugations into a membrane can have three different effects on the water and salt permeability of a membrane.

(1) A change in the morphological structure of the membrane. Lin [7] describes that the performance of hollow fiber membranes was greatly affected by the cold draw ratio of the fiber. He explains this effect to a certain extent by a change in the morphological structure of the fibers.

(2) A change of the thickness of the membrane. The thickness of the membrane is inversely proportional to the increase of surface area caused by the corrugations.

(3) An increase of surface area of the membrane. The measured fluxes are related to the area of a flat membrane. The permeability of the membranes will therefore be dependent on the increase of membrane area caused by the corrugations.

The effects of (2) and (3) can be calculated; they cause the ratio of $A_{\mathrm{c}} / A_{\mathrm{f}}$ and $B_{\mathrm{c}} / B_{\mathrm{f}}$ to be proportional to $\left(S_{\mathrm{c}} / S_{\mathrm{f}}\right)^{2}$, where $A_{\mathrm{c}}$ and $B_{\mathrm{c}}$ are the water and salt permeabilities of a corrugated membrane and $A_{\mathrm{f}}$ and $B_{\mathrm{f}}$ those of a flat membrane. $S_{\mathrm{c}} / S_{\mathrm{f}}$ is the ratio of the surface areas of a corrugated and a flat membrane.

Figs. 4 and 5 show a graph of the ratio $A_{\mathrm{c}} / A_{\mathrm{f}}$ and $B_{\mathrm{c}} / B_{\mathrm{f}}$ versus $\left(S_{\mathrm{c}} / S_{\mathrm{f}}\right)^{2}$. The 


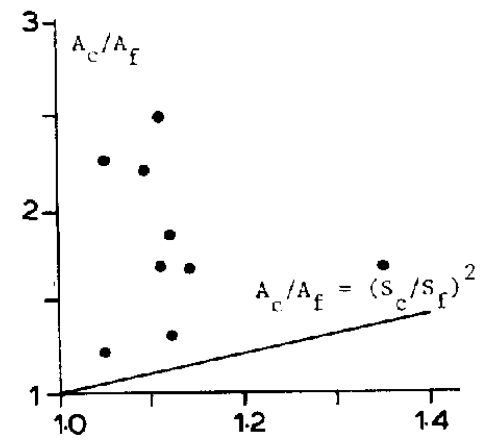

Fig. 4. Ratio $A_{\mathrm{c}} / A_{\mathrm{f}}$ versus $\left(S_{\mathrm{c}} / S_{\mathrm{f}}\right)^{2}$.

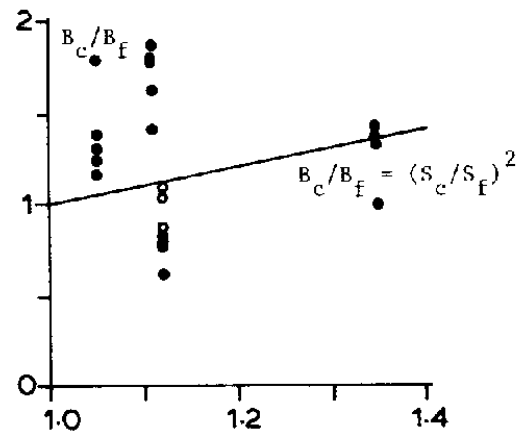

Fig. 5. Ratio $B_{\mathrm{c}} / B_{\mathrm{f}}$ versus $\left(S_{\mathrm{c}} / S_{\mathrm{f}}\right)^{2}$.

deviation from the line $A_{\mathrm{c}} / A_{\mathrm{f}}$ and $B_{\mathrm{c}} / B_{\mathrm{f}}=\left(S_{\mathrm{c}} / S_{\mathrm{f}}\right)^{2}$ might be caused by a change in the morphological structure of the membrane. From these figures some qualitative conclusions can be drawn: the water permeability rises with a factor 1.2 to 3. Change in the morphological structure plays an important role in the increase of the water permeability. The results for the salt permeability show a large spread. Both increase and decrease of salt permeability, due to a change of the morphological structure, have been observed.

\section{Mass transfer}

The ratio $k_{\mathrm{c}} / k_{\mathrm{f}}$ has been plotted against the flow rate $v$ in Fig. 6 for four different plates; $k_{\mathrm{c}}$ and $k_{\mathrm{f}}$ are the mass transfer coefficients for corrugated and flat plates, respectively. It can be seen that due to the turbulence-promoting effect of the corrugations the corrugated plates are more effective than the flat plates and that the corrugated plates are most effective in the low flow region with respect to the mass transfer.

\section{Flux and retention}

For corrugated membranes flux increases of $100 \%$ in comparison with flat membranes at almost the same or even slightly higher retentions have been obtained. Typical results are shown in Table II. In agreement with Eqs. (1) and (4), the simultaneously increasing values of water permeability $A$ and mass transfer coefficient $k$ result in higher values of the permeate flux at the same retention.

\section{Pressure drop}

In Fig. 7 the pressure drop $\Delta P^{\prime}$ in the flow along a flat membrane as well as along some corrugated membranes is given as a function of the flow rate $v$. The 

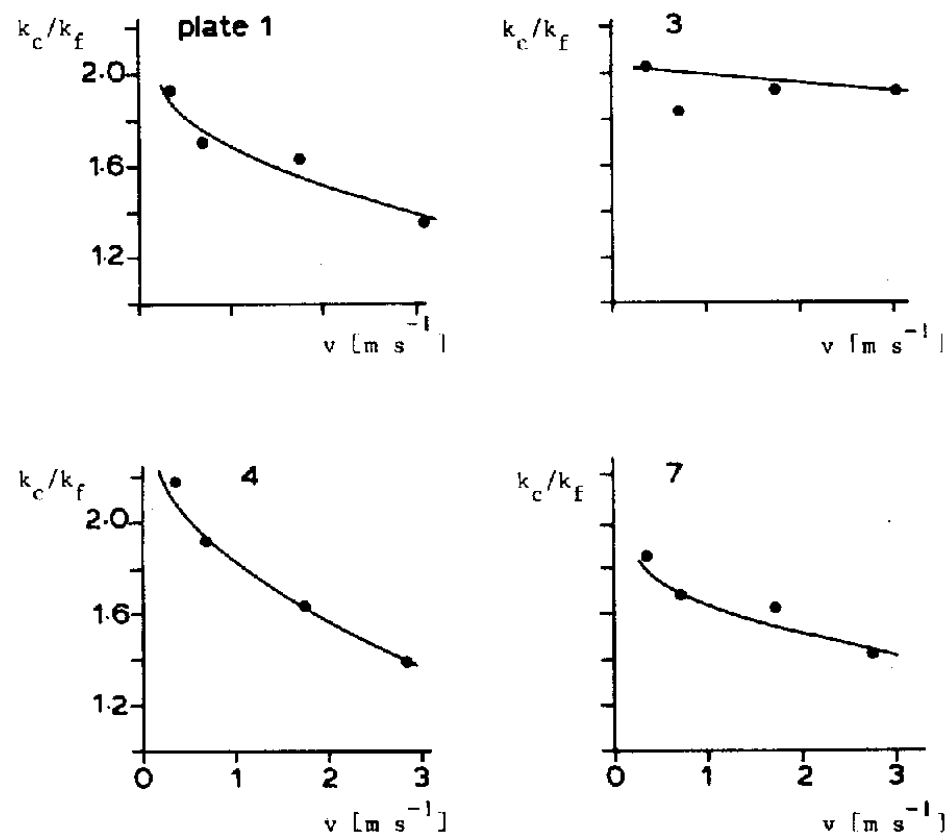

Fig. 6. Ratio $k_{\mathrm{c}} / k_{\mathrm{f}}$ versus $v$ for four different plates. The Reynolds number is $R e=10665 \cdot v$.

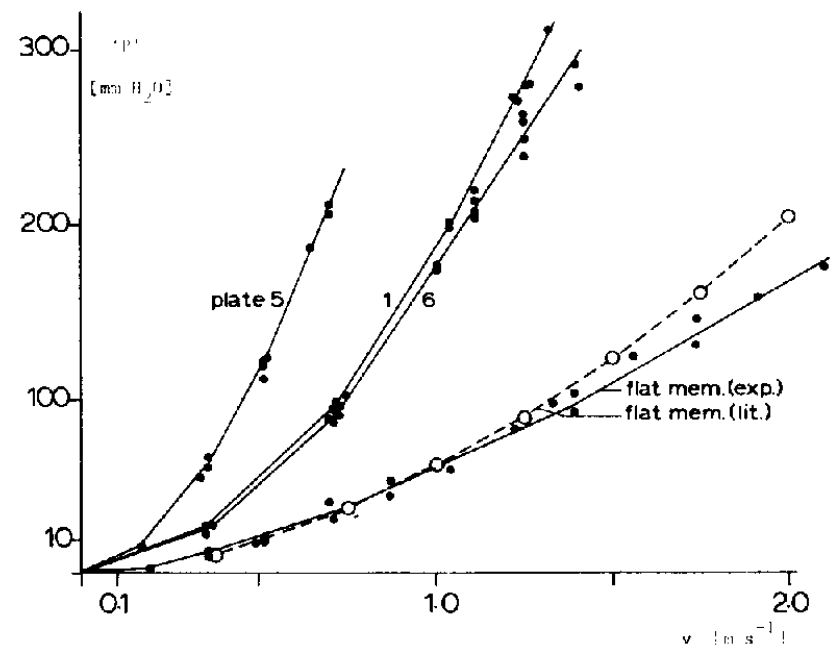

Fig. 7. Pressure drop versus flow rate. The Reynolds number $R e=10665 \cdot v$.

pressure drop along a flat membrane has been compared with a relation from literature for a flow through a straight channel [8]:

$\Delta P^{\prime}=0.316 R e^{-0.25} \cdot \frac{1}{2} \cdot \rho \cdot v^{2} \cdot \frac{l}{d_{h}}$ 
TABLE II

TYPICAL RESULTS FOR $J$ AND $R$, AT $C_{f}=5 \mathrm{~g}^{-1} \mathrm{Na}_{2} \mathrm{SO}_{4}$ AND $\triangle P=40$ BAR, FLOW RATE $v=1 \mathrm{~m} \mathrm{~s}^{-1}$

Flat membrane Corrugated

membrane

Permeate flux $J\left(\mathrm{l} \mathrm{m}^{-2} \mathrm{~s}^{-1}\right) \quad 30 \quad 54$

Retention $R=\frac{C_{f}-C_{p}}{C_{f}} \times 100 \quad 72 \quad 75$

where

$\rho \quad=$ density of fluid $\left(\mathrm{kg} \mathrm{m}^{-3}\right)$

$l=$ length of channel $(\mathrm{m})$

$d_{\mathrm{h}}=$ hydraulic diameter of channel $(\mathrm{m})$

The calculated and measured pressure drop curves are in good agreement as can be seen from Fig. 7. Plates with corrugations of $1.5 \mathrm{~mm}$ height give almost the same pressure drop, independent of the pattern of the corrugations.

Using the measured mass transfer ratio and pressure drop correlations (see Figs. 6 and 7) and the well known mass transfer correlation for turbulent flow [2] it can be determined whether pressing of corrugations into the membrane is an effective way of increasing mass transfer. Table III shows that the corrugations, in a certain range of Reynolds numbers, enhance the mass transfer more effectively than an increase in flow rate on a flat membrane would do.

\section{TABLE III}

FLOW RATE, AVERAGE PRESSURE DROP, MASS TRANSFER RATIO AND PUMPING POWER RATIO FOR FLAT AND CORRUGATED MEMBRANES

\begin{tabular}{lllll}
\hline Membrane & $v\left(\mathrm{~m} \mathrm{~s}^{-1}\right)$ & $k_{\mathrm{c}} / k_{\mathrm{f}}$ & $P_{\mathrm{c}}^{\prime} / P_{\mathrm{f}}^{\prime}$ & $\frac{\text { Pumping power } c}{\text { Pumping power } f}$ \\
\hline Flat & 0.75 & 1 & 0.6 & 0.3 \\
Corrugated & 0.35 & & & \\
\hline Flat & 1.3 & 1 & 0.5 \\
Corrugated & 0.7 & 1 & & \\
\hline
\end{tabular}




\section{CONCLUSIONS}

From the preliminary experiments the following conclusions can be drawn: - Corrugations increase mass transfer in a more effective way than increase of flow rate does.

- Moreover, corrugations can have a positive influence on separation properties of cellulose acetate membranes. A change in the morphological structure of the membrane might hereby play an important role.

We wish to point out that corrugated membranes can be used also in other processes and modules such as ultra- and microfiltration and tubular modules, respectively. The investigation will be continued in our laboratory.

\section{ACKNOWLEDGEMENT}

These investigations were supported in part by the Netherlands Foundation for the Technical Sciences (STW), future Technical Science Branch of the Netherlands Organisation for the Advancement of Pure Research (ZWO).

\section{REFERENCES}

1 J. Hiddink, D. Kloosterboer and S. Bruin, Evaluation of static mixers as convection promoters in ultrafiltration of dairy liquids, Desalination, 35 (1980) 149-167.

2 R. Rautenbach and R. Albrecht, Membrantrennverfahren, Otto Salle Verlag, Frankfurt, 1981.

3 K. Abel, M.A. Jeffree, B.J. Bellhouse and E.L. Bellhouse, A practical secondary flow hemodialyser, Trans. Am. Soc. Artif. Intern. Organs, XXVII (1981) 639-64.

4 M.A. Jeffree, J. Peacock, I.J. Sobey and B.J. Bellhouse, Gel layer limited haemofiltration rates can be increased by vortex mixing, Clin. Exper. Dialysis and Apheresis, 5(4) (1981) 373-380.

$5 \mathrm{H}$. Rybinová, Contribution to the problem of heat transfer and pressure drop in plate heat exchangers, Verfahrenstechnik, 4(9) (1970) 413-417.

6 R. Koch, Druckverlust und Wärmeübergang bei verwirbelter Strömung, VDI Forschungsheft, 469(24) (1958) 1-44.

7 S.Q. Lin, The structure of reverse osmosis hollow fiber membrane of cellulose triacetate, Desalination, 56 (1985) 395-403.

8 W.J. Beek and K.M.K. Muttzall, Transport Phenomena, Wiley, New York, 1980. 